\title{
FONTES E MODOS DE APLICAÇÃO DE FÓSFORO NA PRODUÇÃO E NUTRIÇÃO MINERAL DO MILHO ${ }^{1}$
}

\author{
IVÂNIA BARBOSA ARAÚJO², ANTONIO EDUARDO FURTINI NETO ${ }^{3}$, ÁLVARO VILELA DE \\ RESENDE ${ }^{4}$, VERA MARIA DE CARVALHO ALVES ${ }^{5}$, BRENO RODRIGUES MENDES ${ }^{6}$
}

\begin{abstract}
${ }^{1}$ Extraído da dissertação de Mestrado, apresentada pela primeira autora à Universidade Federal de Lavras - UFLA. Trabalho financiado pelo $C N P q$.

${ }^{2}$ Eng. Agrônoma, Mestre, Departamento de Ciência do Solo da Universidade Federal de Lavras - UFLA. Caixa Postal 37, CEP.37200-000,Lavras, MG.E-mail: ivania.araujo@bol.com.br

${ }^{3}$ Professor Adjunto do Departamento de Ciência do Solo da Universidade Federal de Lavras-UFLA, Pesquisador CNPq. Caixa Postal 37, CEP. 37200-000, Lavras, MG.E-mail: afurtini@ufla.br

${ }^{4}$ Pesquisador, Embrapa Cerrados. Caixa Postal 08223, CEP. 73301-970, Planaltina, DF. E-mail: alvaro@cpac.embrapa.br (autor para correspondência).

${ }_{5}^{5}$ Pesquisadora, Embrapa Milho e Sorgo. Caixa Postal 151, CEP. 35701-970, Sete Lagoas, MG. E-mail: vera@cnpms.embrapa.br

${ }^{6}$ Bolsista PIBIC/CNPq, Departamento de Ciência do Solo da Universidade Federal de Lavras - UFLA.
\end{abstract}

Revista Brasileira de Milho e Sorgo, v.3, n.2, p.250-264, 2004

RESUMO - Com o objetivo de avaliar o efeito de fontes de P, em diferentes modos de aplicação, sobre a produção e nutrição mineral do milho, um experimento foi conduzido em condições de campo, num Argissolo Vermelho típico, textura argilosa, sob vegetação de cerrado. Os tratamentos constituiram-se das fontes de P: superfosfato triplo (ST), termofosfato magnesiano (TM), fosfato reativo de Arad (FR) e fosfato de Araxá (FA), aplicadas em área total ou no sulco de plantio, na dose $180 \mathrm{~kg} \mathrm{ha}^{-1}$ de $\mathrm{P}_{2} \mathrm{O}_{5}$, considerando-se o teor total de $\mathrm{P}_{2} \mathrm{O}_{5}$ das fontes. Utilizou-se, ainda, um tratamento adicional sem aplicação de P. Foram analisados os teores de nutrientes nas folhas do milho no florescimento e em diferentes partes da planta na colheita. Determinaram-se, também, a produção de matéria seca da parte aérea e de grãos e o acúmulo de nutrientes. Maiores produções foram obtidas com as fontes mais solúveis (ST e TM) aplicadas em área total e com o fosfato reativo (FR) no sulco de plantio. O uso localizado de ST no sulco de plantio comprometeu a produtividade da cultura, provocando desordens metabólicas devido à interação $\mathrm{P}$ x Zn. A análise foliar no florescimento mostrou-se adequada para avaliação do equilíbrio $\mathrm{P} / \mathrm{Zn}$ no milho.

Palavras-chave: Adubação fosfatada, fosfatos, análise foliar, interação fósforo-zinco.

\section{PHOSPHORUS SOURCES AND PLACEMENT ON MAIZE YIELD AND MINERAL NUTRITION}

\begin{abstract}
With the aim of evaluating the effect of phosphorus sources in different placement options on maize yield and mineral nutrition, a trial was carried out in field conditions on a clayey Typical Red Argisol under cerrado vegetation. The treatments were: triple superphosphate (TS), magnesium termophosphate (MT), Arad reactive rock phosphate (RP), and Araxá rock phosphate (AP), which were spread on the whole area or banded in the seeding furrow. All fertilizers were applied at the rate of $180 \mathrm{~kg} \mathrm{P}_{2} \mathrm{O}_{5} \mathrm{ha}^{-1}$, based on the total $\mathrm{P}_{2} \mathrm{O}_{5}$ of each fertilizer. A check, without $\mathrm{P}$, was used as an additional
\end{abstract}


treatment. It was measured the nutrient concentrations in the maize leaves at the flowering and in different plant parts at harvest. The shoot dry matter, grain yield, and accumulation of nutrients were also determined. Greater yields were obtained with the most soluble sources (TS and MT) when spread and with the reactive phosphate (RP) banded in the planting furrow. Placement of TS in the planting furrow decreased yield because of metabolic disorders due to the $\mathrm{P}$ and $\mathrm{Zn}$ interaction. The leaf analysis at the flowering showed to be appropriate for maize $\mathrm{P} / \mathrm{Zn}$ balance evaluation.

Key words: Phosphate fertilization, phosphates, leaf analysis, phosphorus-zinc interaction.

A escolha da fonte de fósforo está relacionada tanto à eficiência em suprir as necessidades das plantas, quanto ao custo do fertilizante. Os fosfatos solúveis têm apresentado bons resultados, embora possuam custo mais elevado, ao passo que os fosfatos naturais apresentam baixa solubilidade e menor eficiência agronômica, especialmente para culturas anuais (Goedert \& Lopes, 1987).

O método de aplicação interfere na eficiência dos fertilizantes fosfatados, principalmente em solos com baixo teor de $\mathrm{P}$ e que possuem alta capacidade de fixação do nutriente (Novais \& Smyth, 1999), caso típico dos solos de cerrado. Apesar dos numerosos estudos existentes sobre o manejo da adubação fosfatada, ainda permanecem dúvidas, principalmente quanto à aplicação direta dos fosfatos naturais, importados e nacionais, sendo esse aspecto motivo de controvérsias entre pesquisadores (Lopes, 1999; Novais, 1999).

Fosfatos naturais aplicados a lanço e incorporados em solos com $\mathrm{pH}$ em água até 5,5 têm sua eficiência aumentada com o passar do tempo e com o revolvimento do solo nas operações de aração e gradagem. A aplicação desses fosfatos no sulco de plantio promove redução da eficiência da adubação (Lopes, 1999).

Sob outro ponto de vista, Novais (1999) sugere que a maior solubilização de fosfatos naturais em condições de solos argilosos e com pH ácido não favorece a planta, uma vez que o dreno preferencial do P nesse sistema é o próprio solo, sendo essa situação agravada com o maior contato do fosfato com as partículas de solo propiciado pelo revolvimento. Assim sendo, a aplicação localizada de fosfatos naturais no sulco de plantio levaria a uma condição em que as raízes da planta seriam o principal dreno envolvido na solubilização e aquisição do $\mathrm{P}$, contribuindo para aumentar a eficiência da adubação com esses fertilizantes.

A prática da adubação fosfatada tem implicações na nutrição mineral da planta, podendo interferir na assimilação e função de outros nutrientes. A literatura é farta de trabalhos que associam elevadas concentrações de $\mathrm{P}$ no solo com a indução de deficiência de zinco (Zn), devido às interações que ocorrem entre esses nutrientes no solo e na planta. No entanto, esse tema permanece controvertido e questionamentos têm surgido a respeito da interação $\mathrm{P} x \mathrm{Zn}$, uma vez que os resultados observados em experimentos de casa-de-vegetação tendem a não se confirmar nas condições de campo (Loneragan \& Webb, 1993; Souza et al., 1998).

No presente trabalho, objetivou-se avaliar o efeito da adubação com fontes fosfatadas, em diferentes modos de aplicação, na produção e nutrição mineral do milho em primeiro cultivo.

\section{Material e Métodos}

O experimento foi conduzido em condições de campo (sequeiro) na Fazenda Boa Vista, 
município de Itumirim-MG, situado a $21^{\circ} 19^{\prime} 02^{\prime \prime}$

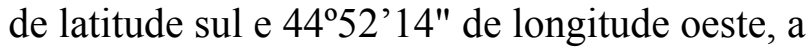
uma altitude média de $871 \mathrm{~m}$. O clima, de acordo com a classificação de Köppen, encontra-se no limite entre $\mathrm{Cwb}$ e Cwa, caracterizando clima temperado a temperado subtropical, com inverno seco. A precipitação pluviométrica durante o período de condução do experimento é apresentada na Figura 1.

A área utilizada apresenta Argissolo Vermelho típico (Podzólico Vermelho-Escuro), textura argilosa, sob vegetação de cerrado e com baixa disponibilidade de fósforo (Tabela 1). A planta-teste foi o milho híbrido triplo HT 971011, desenvolvido pela Embrapa-CNPMS. A área de cada parcela experimental foi de $27 \mathrm{~m}^{2}$, com cinco linhas de seis metros de comprimento, espaçadas de 0,9 metro entre si. Para fins de avaliação, foi considerada uma área útil central de 10,8 $\mathrm{m} 2$ (três linhas de quatro metros de comprimento).

Utilizou-se o delineamento experimental de blocos casualizados, com quatro repetições. Os tratamentos consistiram de um fatorial $4 \times 2+1$, combinando: quatro fontes de fósforo, superfosfato triplo - ST $\left(46,1 \%\right.$ de $\mathrm{P}_{2} \mathrm{O}_{5}$ total e

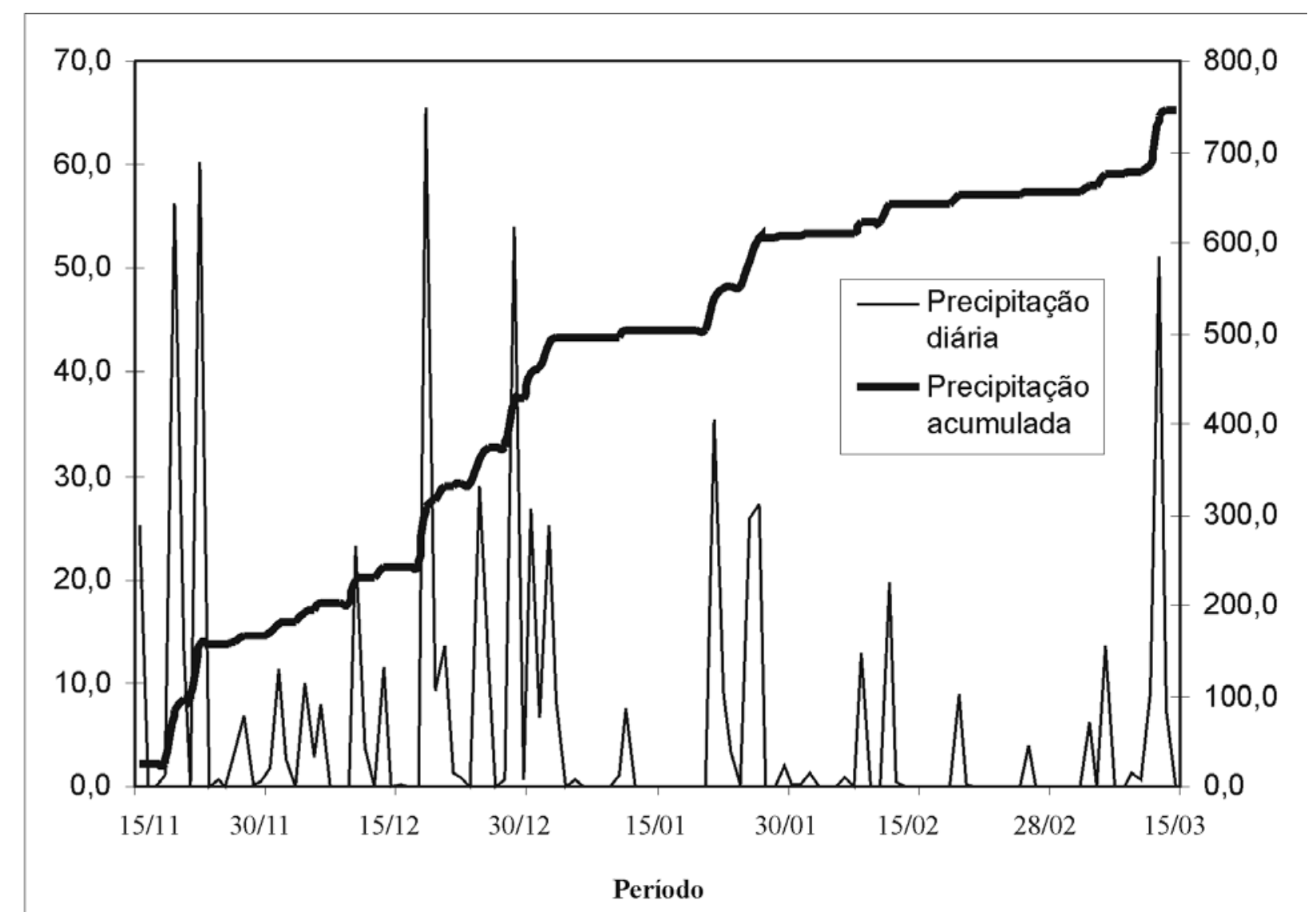

FIGURA 1. Dados pluviométricos (mm de chuva) no período de 15 de novembro de 2000 a 15 de março de 2001. 
$38,3 \%$ solúvel em água), termofosfato magnesiano Yoorin - TM $\left(18,1 \%\right.$ de $\mathrm{P}_{2} \mathrm{O}_{5}$ total e $17,6 \%$ solúvel em ácido cítrico), fosfato reativo de Arad - FR (33,1\% de $\mathrm{P}_{2} \mathrm{O}_{5}$ total e 9,4\% solúvel em ácido cítrico) e fosfato natural de Araxá $\mathrm{FA}\left(22,7 \%\right.$ de $\mathrm{P}_{2} \mathrm{O}_{5}$ total e $4,3 \%$ solúvel em ácido cítrico), em duas formas de aplicação (a lanço em área total e localizada no sulco), sendo que uma testemunha que não recebeu fósforo constituiu o tratamento adicional.

Precedendo ao preparo do solo, foi aplicada uma dose de calcário dolomítico $\left(1,5 \mathrm{t} \mathrm{ha}^{-1}\right)$, determinada previamente pelo método da curva de incubação em laboratório, para elevar o $\mathrm{pH}$ em água próximo a 5,5. Cerca de 40 dias após a incorporação do calcário, foram aplicadas as fontes fosfatadas na dose de $180 \mathrm{~kg} \mathrm{ha}^{-1}$ de $\mathrm{P}_{2} \mathrm{O}_{5}$. O cálculo da quantidade a aplicar de cada fonte foi realizado, baseando-se no teor de $\mathrm{P}_{2} \mathrm{O}_{5}$ total dos fertilizantes. Todo o fósforo foi aplicado na época do plantio. No modo de aplicação a lanço, os fertilizantes foram distribuídos manualmente em toda a área da parcela experimental e incorporados a $10 \mathrm{~cm}$ de profundidade. Na aplicação localizada, os fertilizantes foram distribuídos no fundo do sulco de semeadura.

$\mathrm{Na}$ semeadura, foram aplicados $21 \mathrm{~kg} \mathrm{ha-}$ ${ }^{1}$ de $\mathrm{N}$ (sulfato de amônio), $90 \mathrm{~kg} \mathrm{ha}^{-1}$ de $\mathrm{K}_{2} \mathrm{O}$ (cloreto de potássio), e $2 \mathrm{~kg} \mathrm{ha}^{-1}$ de $\mathrm{Zn}$ (sulfato de zinco) na linha de semeadura, sendo essas doses determinadas de acordo com a análise do solo e as recomendações de adubação do milho para

TABELA 1. Principais atributos químicos do solo $(0-20 \mathrm{~cm}$ de profundidade $)$ aos 25 dias após a semeadura do milho.

\begin{tabular}{|c|c|c|c|c|c|c|c|c|c|}
\hline \multirow{2}{*}{ Fontes de $\mathrm{P}$} & \multirow{2}{*}{$\mathrm{pH}\left(\mathrm{H}_{2} \mathrm{O}\right)$} & $\mathbf{P}^{1}$ & $\mathbf{K}$ & $\mathrm{Ca}$ & Mg & Al & $\mathbf{H}+\mathbf{A l}$ & $\mathbf{V}$ & $\mathbf{m}$ \\
\hline & & \multicolumn{2}{|c|}{$\mathrm{mg} \mathrm{dm}^{-3}$} & \multicolumn{4}{|c|}{ cmol $_{\mathrm{c}} \mathrm{dm}^{-3}$} & \multicolumn{2}{|c|}{$\%$} \\
\hline \multicolumn{10}{|c|}{ Lanço } \\
\hline ST & 5,0 & 9,7 & 206 & 1,6 & 0,5 & 0,5 & 6,5 & 29,7 & 17,3 \\
\hline TM & 5,2 & 12,6 & 232 & 1,8 & 0,6 & 0,4 & 5,4 & 35,5 & 12,7 \\
\hline FR & 5,0 & 10,6 & 224 & 1,2 & 0,4 & 0,6 & 6,2 & 26,0 & 23,7 \\
\hline FA & 4,9 & 7,1 & 182 & 1,4 & 0,7 & 0,6 & 6,1 & 28,9 & 23,7 \\
\hline \multicolumn{10}{|c|}{ Sulco } \\
\hline ST & 5,1 & 22,9 & 157 & 1,9 & 0,6 & 0,4 & 5,9 & 33,2 & 14,3 \\
\hline TM & 5,1 & 46,1 & 171 & 1,8 & 1,1 & 0,3 & 4,8 & 39,6 & 9,7 \\
\hline FR & 5,0 & 21,4 & 185 & 1,4 & 0,6 & 0,5 & 5,4 & 31,4 & 16,7 \\
\hline FA & 4,8 & 17,4 & 184 & 1,4 & 0,3 & 0,6 & 5,9 & 26,6 & 25,7 \\
\hline Testemunha & 4,8 & 7,8 & 196 & 1,3 & 0,6 & 0,6 & 6,3 & 26,9 & 22,3 \\
\hline
\end{tabular}

${ }^{1} \mathrm{P}$ disponível pela resina de troca iônica. Interpretação: 0-6 = muito baixo, $7-15=$ baixo, $16-40=$ médio, $41-80=$ alto, $>80=$ muito alto (Raij et al., 1996).

Caracterização da área antes da aplicação dos tratamentos: $\mathrm{P}$ disponível $=7,8 \mathrm{mg} \mathrm{dm}{ }^{-3}$; matéria orgânica, areia, silte e argila $=33,350,140$ e $510 \mathrm{~g} \mathrm{~kg}^{-1}$, respectivamente. 
o Estado de Minas Gerais (Alves et al., 1999). A semeadura foi realizada no dia 25 de novembro de 2000, distribuindo-se dez sementes por metro linear de sulco. Posteriormente, foi realizado desbaste, mantendo-se cinco plantas por metro. Três adubações de cobertura com uréia foram realizadas ao longo do ciclo vegetativo da cultura, totalizando $170 \mathrm{~kg} \mathrm{ha}^{-1}$ de $\mathrm{N}$.

Amostras de solo foram coletadas na área antes da aplicação dos tratamentos e aos vinte e cinco dias após a semeadura do milho nas linhas de plantio das parcelas, para caracterização dos tratamentos (Tabela 1). Dados de pH, Ca, Mg, Al e $\mathrm{K}$ foram obtidos com base nos métodos da Embrapa (1997): pH em água, relação 1:2,5; Ca, $\mathrm{Mg}$ e $\mathrm{Al}$ usando extrator $\mathrm{KCl} \mathrm{mol} \mathrm{L}^{-1}$; $\mathrm{K}$ pelo extrator Mehlich-1. O P disponível foi determinado com resina de troca iônica (Raij \& Quaggio, 1983).

No florescimento, foram coletadas folhas de seis plantas por parcela (primeira folha oposta e abaixo da espiga) e determinados os teores foliares de macro e micronutrientes, conforme metodologia descrita por Malavolta et al. (1997). Por ocasião da colheita, avaliou-se a produção de matéria seca da parte aérea, de espigas e de grãos na área útil das parcelas. Duas plantas e cinco espigas representativas de cada parcela foram coletadas para a determinação da concentração de nutrientes nas folhas, colmo + pendão, palha, sabugo e grãos. Considerando-se os teores de nutrientes nas diferentes partes da planta e os respectivos pesos secos, foram obtidos os conteúdos de nutrientes (acúmulo) nesses compartimentos.

Os dados experimentais foram submetidos a análises de variância. Utilizou-se o teste de Tukey $(p<0,05)$ para comparação de médias dos tratamentos do fatorial e contrastes (teste F, $p<0,05)$ para comparar a média do fatorial com o tratamento testemunha.

\section{Resultados e Discussão}

A população final das plantas não foi afetada pelos tratamentos. Verificou-se efeito do modo de aplicação e da fonte de fósforo sobre o número de espigas produzidas pelo milho, não havendo, contudo, interação desses fatores. O tratamento-testemunha produziu o equivalente a 54.737 espigas $\mathrm{ha}^{-1}$, sendo estatisticamente inferior à média do fatorial. A aplicação do fósforo a lanço levou à produção de maior número de espigas (58.391), comparativamente ao fornecimento localizado do nutriente (56.837). Considerando a falta de chuva em determinadas fases do período experimental (Figura 1), tal resultado pode estar associado à maior eficiência de absorção de água quando, estimulado pela presença do fósforo distribuído em área total, o sistema radicular explora maior volume de solo externamente à linha de semeadura.

Obtiveram-se produções médias equivalentes a 59.331(a), 58.997(a), 55.970(b) e 55.834(b) espigas ha $^{-1}$, respectivamente para as fontes ST, TM, FR e FA. As diferenças estatísticas são indicativas de que os fosfatos mais solúveis (ST e TM) favoreceram a produção de mais de uma espiga por planta. De acordo com Mengel \& Kirkby (1987), a pronta liberação do P na fase inicial da cultura está relacionada ao aumento do número de espigas por área.

$\mathrm{Na}$ aplicação a lanço, as fontes mais solúveis (ST, TM) promoveram maior peso de grãos (Tabela 2). Todavia, estatisticamente, não diferiram em relação ao fosfato de Araxá (FA). Quando da aplicação no sulco de plantio, a produção com o FA foi menor que aquela obtida com o uso das demais fontes. À exceção do tratamento com fosfato reativo, os valores absolutos da produção de grãos foram mais elevados quando os fertilizantes foram distribuídos a lanço em área total (Tabela 2). 
TABELA 2. Produção de grãos $\left(\mathrm{kg} \mathrm{ha}^{-1}\right)$ em função de fontes e modos de aplicação de fósforo na cultura do milho.

\begin{tabular}{lcccc}
\hline \multirow{2}{*}{ Modos de aplicação } & \multicolumn{5}{c}{ Fontes } \\
\cline { 2 - 5 } & \multicolumn{1}{c}{ ST } & TM & FR & FA \\
\hline Lanço & 8.369 a A & 8.436 a A & $6.831 \mathrm{~b} \mathrm{~B}$ & 7.334 a AB \\
Sulco & 7.454 a AB & 7.608 a AB & 8.397 a A & 6.047 a B \\
\hline
\end{tabular}

Testemunha

$6.875^{*}$

Médias seguidas pelas mesmas letras minúsculas na coluna e maiúsculas na linha não diferem entre si (Tukey, $p<0,05)$.

*Média do tratamento testemunha difere $(<)$ em relação à média do fatorial (teste $\mathrm{F}, p<0,05)$.

De acordo com Goedert \& Souza (1986), as fontes solúveis geralmente apresentam desempenho similar para ambas as formas de aplicação, podendo a aplicação a lanço promover maiores rendimentos em relação à aplicação localizada em função de déficit hídrico. Já os termofosfatos, fosfatos reativos (Goedert \& Lobato, 1984) e fosfatos naturais brasileiros (Lopes, 1999) aplicados a lanço apresentam maior eficiência. Outros pesquisadores, entretanto, têm relatado resultados e indicado recomendações de adubação contrários a essas sugestões (Anghinoni, 1992; Kaminsky \& Peruzzo, 1997; Novais, 1999; Novais \& Smyth, 1999).

No caso dos fosfatos naturais FR e FA aplicados a lanço, além da baixa solubilidade característica dessas fontes (9,4 e 4,3\% solúvel em ácido cítrico, respectivamente), a falta de umidade por determinados períodos no decorrer do ciclo do milho (Figura 1) e a limitação de tempo para a ocorrência dos processos de solubilização, possivelmente, concorreram para restringir a liberação de $\mathrm{P}$ em quantidades ótimas para o cultivo de milho, o que não foi crítico no caso do ST e TM que, sendo mais solúveis, provavelmente supriram a demanda da cultura.

A influência do modo de aplicação no desempenho das fontes foi mais acentuada para o FR. A aplicação dessa fonte no sulco promoveu o maior ganho em produção de grãos (Tabela 2). Kaminsky \& Peruzzo (1997) apresentam resultados para a cultura da soja nos quais a aplicação do fosfato reativo de Arad (FR) na linha de plantio também promoveu maior rendimento de grãos, comparativamente à distribuição do produto a lanço. Esses resultados podem ser atribuídos ao aumento da concentração de $\mathrm{P}$ próximo às raízes e também à redução da fixação em função do menor contato do fertilizante com o solo, disponibilizando mais o nutriente às plantas, ao passo que a aplicação a lanço tende a favorecer o solo e não a planta, conforme relatado por Anghinoni (1992) e Novais (1999). No presente trabalho, tal constatação parece aplicar-se somente ao FR.

Esperava-se um comportamento diferenciado do FA quanto à produção de grãos, em virtude da baixa taxa de liberação do nutriente por essa fonte, não atendendo às exigências da cultura no primeiro ano após a aplicação, conforme sugerido por Goedert \& Lopes (1987) e Lopes (1998, 1999), o que não ocorreu de forma evidente no presente estudo. Por outro lado, o fato de que os rendimentos obtidos com a utilização dessa fonte não diferiram das fontes mais solúveis (Tabela 2) pode ser indicativo de uma alta 
eficiência do genótipo de milho a fósforo. Os dados médios de produtividade relativamente elevados em todos os tratamentos, incluindo a testemunha, reforçam tal comportamento do genótipo.

A dose relativamente alta de $\mathrm{P}_{2} \mathrm{O}_{5}(180$ $\mathrm{kg} \mathrm{ha}^{-1}$ ) utilizada pode ter contribuído para minimizar os efeitos do modo de aplicação dos fertilizantes sobre a produção do milho, apesar das diferenças de solubilidade dos mesmos. Conforme apontado por Kaminsky \& Peruzzo (1997), é provável ocorrerem alterações dos resultados num segundo cultivo, devido ao efeito residual de cada tratamento.

De maneira geral, os teores médios de macro e micronutrientes (Tabela 3 ) na folha abaixo da espiga principal, por ocasião do florescimento, situaram-se dentro das faixas de valores tidas como adequadas para o milho, conforme os níveis de interpretação propostos por diversos autores citados por Büll (1993). Entretanto, para os tratamentos com fosfato de Araxá aplicado a lanço e testemunha, os teores foliares de fósforo (Tabela 3) ficaram abaixo do limite que corresponde à faixa adequada, coerentemente com a menor disponibilidade do nutriente esperada nesses tratamentos.

Em relação aos micronutrientes, apenas o $\mathrm{Zn}$ apresentou comportamento diferenciado. $\mathrm{O}$ menor teor foliar foi observado quando se aplicou superfosfato triplo no sulco de plantio (Tabela 3), sendo o único tratamento em que não se alcançou a faixa de suficiência (15-50 mg kg-1) de zinco indicada para a cultura (Büll, 1993; Malavolta, et al., 1997). Considerando que a produção de matéria seca da parte aérea no referido tratamento foi semelhante àquela obtida com outras fontes e modo de aplicação, descarta-se a possibilidade de um efeito de diluição do zinco absorvido (Jarrel \& Beverly, 1981). Pressupõe-se, portanto, que houve restrição do aproveitamento do micronutriente, em virtude do excesso de $\mathrm{P}$ liberado pela maior concentração e rápida solubilização do superfosfato triplo aplicado no sulco, ocasionando a interação antagônica $\mathrm{P} x \mathrm{Zn}$ (Büll, 1993), pela qual, altos níveis de fósforo disponível no solo podem induzir a deficiência de zinco.

Essa constatação é importante, pois trata-se, de um evento que pode, pelo menos em parte, explicar os baixos valores de produção de grãos (Tabela 2) inesperadamente obtidos com a aplicação localizada de uma fonte de fósforo de alta solubilidade (ST), comparativamente a outros tratamentos do presente trabalho. A presença de zinco na planta está relacionada a processos de síntese de substâncias promotoras de crescimento, como o ácido indolacético (AIA), e sua deficiência no milho acarreta prejuízo ao crescimento e produção de grãos (Decaro et al., 1983; Ritchey et al., 1986).

Destaca-se que, nas condições experimentais do presente estudo e, baseando-se em patamares de produção bastante significativos (Tabela 2), ganhos adicionais em produtividade não são modulados apenas pela disponibilidade de nutrientes, passando a ser extremamente dependentes de relações adequadas entre esses nutrientes, bem como de condições externas (ambientais) favoráveis.

As médias dos teores de macro e micronutrientes na planta de milho ao final do ciclo, à exceção do $\mathrm{P}$, não mostraram diferenças em função dos tratamentos. Não foram verificados efeitos dos tratamentos nos teores de $\mathrm{P}$ no colmo + pendão e sabugo do milho.

Em consonância com o efeito dos tratamentos sobre a disponibilidade de P no solo (Tabela 1), o teor do nutriente nas folhas ao final do ciclo do milho foi superior quando as plantas 


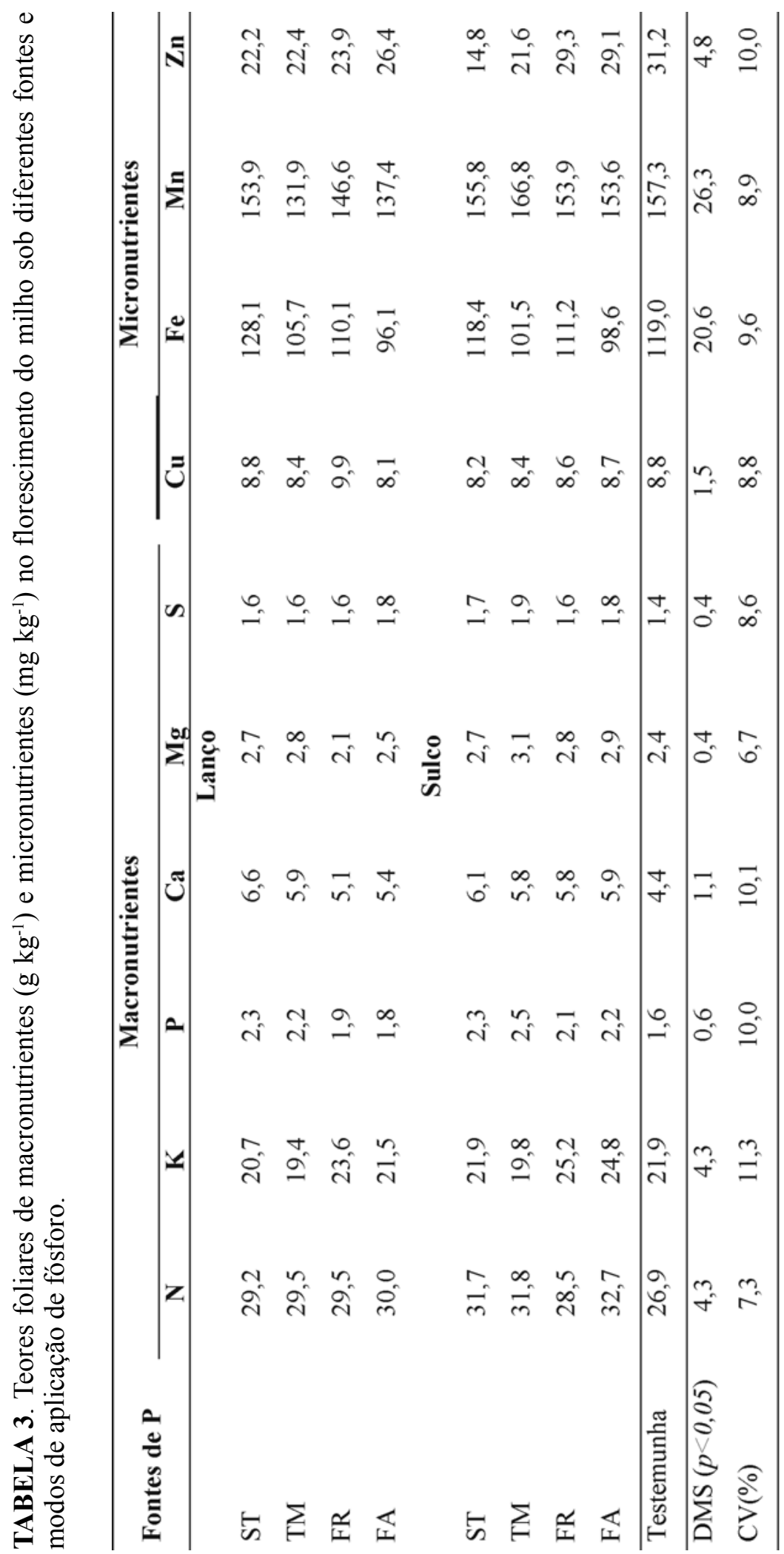


receberam adubação fosfatada de forma localizada (Tabela 4), sem, contudo, haver interação entre fontes e modos de aplicação.

Para os teores de P na palha e nos grãos, houve interação significativa de fontes e modos de aplicação. Verificou-se diferença de magnitude dos teores de $\mathrm{P}$ em diferentes partes do milho, ocorrendo destacada superioridade dos teores de $P$ nos grãos (Tabela 5) em relação àqueles presentes em outros compartimentos da planta.

Até $80 \%$ do $\mathrm{P}$ absorvido pelo milho pode ser direcionado para os grãos (Büll, 1933; Cantarella, 1993). Após a polinização, o suprimento de $\mathrm{P}$ para os grãos em desenvolvimento é bastante intenso. A absorção de $\mathrm{P}$ pelas raízes é ainda muito ativa durante o período de formação da espiga até sua maturidade. Nesse período, a quantidade de $\mathrm{P}$ absorvida pelas raízes varia de 43 a $65 \%$ de todo o $\mathrm{P}$ absorvido pela planta e a maior parte destina-se aos grãos em desenvolvimento. A redistribuição do $\mathrm{P}$ ocorre das folhas para $\mathrm{o}$ colmo, espiga e palha, sendo a maior parte do $\mathrm{P}$ total presente nas partes vegetativas direcionada para a espiga (Arnon, 1975).

A aplicação localizada dos fertilizantes no sulco de plantio ocasionou maiores teores de P nos grãos, à exceção do superfosfato triplo (ST), que apresentou tendência contrária (Tabela 5).

TABELA 4. Teores de $\mathrm{P}\left(\mathrm{g} \mathrm{kg}^{-1}\right)$ em folhas de milho ao final do ciclo em função do fornecimento e do modo de aplicação do nutriente na adubação.

\begin{tabular}{lclcc}
\hline \multicolumn{2}{c}{ Fornecimento de P } & & \multicolumn{2}{c}{ Modos de aplicação } \\
\cline { 1 - 2 } \cline { 5 - 5 } Fatorial (com P) & $0,48 \mathrm{a}$ & & Lanço & $0,43 \mathrm{~b}$ \\
Testemunha (sem P) & $0,33 \mathrm{~b}$ & & Sulco & $0,53 \mathrm{a}$ \\
\hline
\end{tabular}

Médias seguidas por letras distintas na coluna diferem entre si (Tukey, $p<0,05$ ).

TABELA 5. Teores de $\mathrm{P}\left(\mathrm{g} \mathrm{kg}^{-1}\right)$ na palha e nos grãos de milho em função de fontes e modos de aplicação do nutriente.

\begin{tabular}{|c|c|c|c|c|c|}
\hline \multirow{2}{*}{ Modos de aplicação } & \multicolumn{4}{|c|}{ Fontes } & \multirow{2}{*}{ Testemunha } \\
\hline & ST & TM & FR & FA & \\
\hline & \multicolumn{5}{|c|}{ Palha } \\
\hline Lanço & $0,26 \mathrm{~b} \mathrm{AB}$ & 0,39 a $\mathrm{A}$ & $0,30 \mathrm{~b} \mathrm{AB}$ & $0,33 \mathrm{a} A B$ & \multirow{2}{*}{$0,30 \mathrm{~ns}$} \\
\hline \multirow[t]{2}{*}{ Sulco } & 0,36 a A & $0,26 \mathrm{~b} \mathrm{~B}$ & 0,43 a $\mathrm{A}$ & 0,37 a $A$ & \\
\hline & \multicolumn{5}{|c|}{ Grãos } \\
\hline Lanço & 4,90 a $\mathrm{A}$ & $4,01 \mathrm{~b} \mathrm{AB}$ & 4,17 b A & $2,97 \mathrm{~b} \mathrm{~B}$ & \multirow{2}{*}{$3,92 \mathrm{~ns}$} \\
\hline Sulco & $3,47 \mathrm{~b} \mathrm{C}$ & 5,92 a $\mathrm{A}$ & 5,19 a $\mathrm{AB}$ & 4,69 a $\mathrm{A}$ & \\
\hline
\end{tabular}

Médias seguidas pelas mesmas letras minúsculas na coluna e maiúsculas na linha não diferem entre si (Tukey, $p<0,05)$.

ns - média do tratamento testemunha não difere em relação à média do fatorial (teste $\mathrm{F}, p<0,05$ ). 
Teoricamente, a aplicação de uma fonte de alta solubilidade num restrito volume de solo (ST no sulco), representaria maior concentração de $\mathrm{P}$ em solução desde o início do ciclo da cultura (Novais \& Smyth, 1999), proporcionando teor do nutriente mais elevados na planta. Como já inferido, as causas do resultado obtido no presente trabalho podem estar relacionadas aos efeitos desfavoráveis da interação $\mathrm{P} x \mathrm{Zn}$ sobre o metabolismo do milho nesse tratamento.

Para o conteúdo de $\mathrm{P}$ na parte aérea, excluindo-se a espiga, não houve efeito diferenciado das fontes dentro de cada modo de aplicação, enquanto que, para o acúmulo na palha + sabugo, foram observadas pequenas variações. Em todos os tratamentos, a maior parte do $\mathrm{P}$ absorvido foi mobilizada para os grãos (Tabela 6), confirmando os relatos de Clark (1975) de que espigas e grãos constituem os órgãos de maior armazenamento de fósforo por ocasião da maturidade das plantas de milho.

Dado o caráter de forte dreno de $\mathrm{P}$, o compartimento grãos pareceu refletir diferenças mais sutis quanto à intensidade do suprimento externo do nutriente nos diversos tratamentos do presente trabalho, considerando-se a solubilidade e forma de distribuição dos fertilizantes.

TABELA 6. Conteúdo de $\mathrm{P}\left(\mathrm{kg} \mathrm{ha}^{-1}\right)$ nas plantas de milho em função de fontes e modos de aplicação de fósforo.

\begin{tabular}{lcccc}
\hline Modos de & \multicolumn{4}{c}{ Fontes } \\
\cline { 2 - 5 } aplicação & ST & TM & FR & FA \\
\hline \multirow{2}{*}{ Lanço } & 8,23 b A (16\%) & 9,63 a A $(21 \%)$ & 7,90 b A (21\%) & 9,45 a A (28\%) \\
Sulco & 11,03 a A (28\%) & 9,26 a A $(17 \%)$ & 10,63 a A (19\%) & 9,52 a A (22\%) \\
& & \multicolumn{4}{c}{ Palha + Sabugo } \\
Lanço & 1,88 a A (4\%) & 2,44 a A (5\%) & 1,77 b A (4\%) & 1,91 a A (6\%) \\
Sulco & 1,86 a AB (5\%) & 1,73 b B (4\%) & 2,52 a A (4\%) & 1,89 a AB (5\%) \\
& & 4 & Grão & \\
Lanço & 40,87 a A (80\%) & 33,77 b AB (74\%) & 28,47 b BC (75\%) & 22,38 b C (66\%) \\
Sulco & 25,89 b B (67\%) & 45,09 a A (79\%) & 43,27 a A (77\%) & 31,21 a B (73\%) \\
& & \multicolumn{2}{c}{ Total na parte aérea } & \\
Lanço & 50,98 a A (100\%) & 45,85 b A (100\%) & 38,13 bBC(100\%) & 33,74 b C (100\%) \\
Sulco & 38,78 b B (100\%) & 56,07 a A (100\%) & 56,42 a A (100\%) & 42,62 a B (100\%) \\
\hline
\end{tabular}

O valor expresso em porcentagem após cada média indica a participação do compartimento em relação ao conteúdo total de $\mathrm{P}$ na parte aérea.

Testemunha: Folha + Colmo $=7,26 *(20 \%)$; Palha + Sabugo $=1,58 *(5 \%)$; Grão $=27,12 *(75 \%)$; Total na parte aérea $=35,96^{*}(100 \%)$.

Médias seguidas pelas mesmas letras minúsculas na coluna e maiúsculas na linha não diferem entre si (Tukey, $p<0,05)$.

* Média do tratamento testemunha difere $(<)$ em relação à média do fatorial (teste $\mathrm{F}, p<0,05)$. 
À exceção do ST no sulco, observa-se que, conforme esperado, o uso de fontes mais solúveis (TM), com rápida liberação de $\mathrm{P}$ após a aplicação e a distribuição de forma localizada ocasionaram maior absorção de fósforo, conforme evidenciado pelos acúmulos total e nos grãos (Tabela 6). Esses resultados corroboram as tendências esperadas, pois, na aplicação localizada e, principalmente no caso de fontes de maior solubilidade, pequeno volume de solo é saturado com o P liberado dos fertilizantes e os sítios de adsorção nos componentes do solo são inicialmente ocupados (dreno-solo), ficando mais disponível o restante do $\mathrm{P}$ proveniente dessas fontes, favorecendo a absorção pelas raízes (drenoplanta) (Novais \& Smyth, 1999).

Com exceção do zinco, o acúmulo total na parte aérea dos demais macro e micronutrientes manteve-se relativamente constante, independente dos tratamentos. Os conteúdos de zinco em diferentes partes da planta foram influenciados pelos tratamentos, sendo, de maneira geral, mais elevados na ausência da adubação fosfatada (testemunha) ou no caso do uso de fontes menos solúveis (especialmente o FA) aplicadas no sulco (Tabela 7). Dessa forma, parece que a maior absorção de $\mathrm{Zn}$ é condicionada pela presença de menores concentrações de $\mathrm{P}$ em solução (confirmada pela liberação mais lenta do nutriente pelas fontes FR e FA) e quando as raízes concentram-se nas proximidades do sulco, local de aplicação da adubação de base com o micronutriente.

O conteúdo de $\mathrm{Zn}$ nos grãos (Tabela 7) não apresentou clara ligação com os tratamentos de adubação fosfatada e nem com os teores foliares do micronutriente por ocasião do florescimento (Tabela 3). Entretanto, os conteúdos totais, em todos os tratamentos, foram superiores ao valor de $400 \mathrm{~g} \mathrm{ha}^{-1}$ correspondente a uma produção de 9,1 ton ha-1 de grãos (Gamboa, 1980), a qual ultrapassa as maiores produtividades alcançadas no presente experimento. Esse fato permite inferir que a produção de grãos, no tratamento ST no sulco, foi afetada negativamente não somente devido a problemas de absorção ou translocação de $\mathrm{Zn}$, mas pela ocorrência de desbalanço nutricional ocorrido no florescimento, fase crítica da cultura, causando redução no rendimento de grãos.

Avaliando as respostas do milho ao fornecimento de $\mathrm{P}$ e Zn num Latossolo VermelhoEscuro textura média, Souza et al. (1998) concluíram não ter havido influência significativa da aplicação de até $200 \mathrm{~kg} \mathrm{ha}^{-1}$ de $\mathrm{P}_{2} \mathrm{O}_{5}$ no sulco de semeadura sobre os teores foliares de Zn. Entretanto, produtividades mais elevadas somente foram obtidas com a aplicação do micronutriente.

Malavolta et al. (1997) relatam que os efeitos detrimentais da interação $\mathrm{P} x \mathrm{Zn}$ podem ter como causas, a insolubilização do $\mathrm{Zn}$ pelo fosfato na superfície das raízes (reduzindo a absorção), a inibição não-competitiva da absorção de Zn pelo $\mathrm{P}$, ou a insolubilização no xilema (prejudicando o transporte para a parte aérea das plantas). Segundo diversos autores citados por Büll (1993), a interação $\mathrm{P} x \mathrm{Zn}$ pode também estar ligada a uma desordem metabólica, devido ao desbalanceamento entre esses nutrientes. A excessiva concentração de $\mathrm{P}$ interfere na função metabólica do $\mathrm{Zn}$ em certos sítios nas células (Olsen, 1972).

As observações relativas ao acúmulo de Zn no milho (Tabela 7) permitem concluir que, no caso do genótipo estudado, a interação $\mathrm{P} x \mathrm{Zn}$ ocorre, apenas em parte, pelo mecanismo de restrição da absorção do micronutriente pela elevada quantidade de $\mathrm{P}$ solúvel nas proximidades da raiz (vide acúmulo total na parte aérea no tratamento-testemunha e FA, comparativamente ao 
TABELA 7. Conteúdo de $\mathrm{Zn}\left(\mathrm{g} \mathrm{ha}^{-1}\right)$ na planta de milho em função de fontes e modos de aplicação de fósforo.

\begin{tabular}{|c|c|c|c|c|c|}
\hline \multirow{2}{*}{$\begin{array}{l}\text { Modos de } \\
\text { aplicação }\end{array}$} & \multicolumn{4}{|c|}{ Fontes } & \multirow{2}{*}{ Testemunha } \\
\hline & ST & TM & FR & FA & \\
\hline & \multicolumn{5}{|c|}{ Folha + Colmo } \\
\hline Lanço & 264 a A & 394 a A & 389 a A & $432 \mathrm{~b} \mathrm{~A}$ & \multirow{2}{*}{$568^{*}$} \\
\hline \multirow[t]{2}{*}{ Sulco } & 316 a B & 319 a B & $512 \mathrm{a} A B$ & 721 a A & \\
\hline & \multicolumn{5}{|c|}{ Palha + sabugo } \\
\hline Lanço & 61 a B & 87 a $\mathrm{A}$ & 55 a B & 77 a $\mathrm{AB}$ & \multirow{2}{*}{$88^{*}$} \\
\hline \multirow[t]{2}{*}{ Sulco } & 32 b B & $48 \mathrm{~b} \mathrm{AB}$ & 70 a $\mathrm{A}$ & 68 a A & \\
\hline & & & Grão & & \\
\hline Lanço & 268 a A & 306 a A & 269 a A & 259 a A & \multirow{2}{*}{$295 \mathrm{~ns}$} \\
\hline \multirow[t]{2}{*}{ Sulco } & 268 a A & 301 a A & 318 a A & 267 a A & \\
\hline & \multicolumn{5}{|c|}{ Total na Parte aérea } \\
\hline Lanço & 594 a A & 786 a A & 709 a A & $761 \mathrm{~b} \mathrm{~A}$ & \multirow{2}{*}{$949^{*}$} \\
\hline Sulco & 617 a B & 668 a B & 881 a $\mathrm{AB}$ & 994 a A & \\
\hline
\end{tabular}

Médias seguidas pelas mesmas letras minúsculas na coluna e maiúsculas na linha não diferem entre si (Tukey, $p<0,05)$.

* Média do tratamento testemunha difere $(>$ ) em relação à média do fatorial (teste $\mathrm{F}, p<0,05)$. ns - média do tratamento testemunha não difere em relação à média do fatorial (teste $\mathrm{F}, p<0,05$ ).

acúmulo nas fontes mais solúveis ST e TM no sulco). O transporte de Zn na planta, aparentemente não foi comprometido, visto que as diferentes partes da planta ao final do ciclo apresentam aporte equilibrado do micronutriente entre os tratamentos.

Nesse contexto, a probabilidade de terem ocorrido desordens metabólicas em conseqüência do desbalanço de $\mathrm{P}$ e $\mathrm{Zn}$ é reforçada pelos dados de relação entre esses nutrientes (Tabela 8) na folha amostrada à época do florescimento que, certamente, melhor expressa o estado nutricional do milho no período de mais intensa atividade metabólica da planta. Conforme sugerido por Sumner \& Farina (1986), o valor de 152 observado para a relação $\mathrm{P} / \mathrm{Zn}$ no tratamento com superfosfato no sulco (Tabela 8) encontra-se numa faixa de acentuada possibilidade de comprometimento da produção de grãos, inclusive podendo levar ao surgimento de sintomas visuais de deficiência do micronutriente. Todavia, no presente estudo, foi constatada perda de produtividade sem sintomas aparentes da carência de zinco.

$\mathrm{Na}$ agricultura moderna, sem a devida observância da capacidade tampão de fosfato dos solos, com freqüência têm sido empregadas doses elevadas de fontes solúveis com aplicação localizada na linha de plantio, ocasionando alta concentração de $\mathrm{P}$ próximo às raízes, o que pode provocar redução da produção em virtude de desbalanço nutricional, caso não se tenha aporte 
Araújo et al.

TABELA 8. Relação de teores $\mathrm{P} / \mathrm{Zn}$ nas folhas de milho no florescimento e ao final do ciclo em função de fontes e modos de aplicação de fósforo.

\begin{tabular}{|c|c|c|c|c|c|}
\hline \multirow{2}{*}{$\begin{array}{l}\text { Modos de } \\
\text { aplicação }\end{array}$} & \multicolumn{4}{|c|}{ Fontes } & \multirow{2}{*}{ Testemunha } \\
\hline & ST & TM & FR & FA & \\
\hline & \multicolumn{5}{|c|}{ Folha no florescimento } \\
\hline Lanço & 104 & 98 & 79 & 70 & \\
\hline \multirow[t]{2}{*}{ Sulco } & 152 & 114 & 72 & 75 & 31 \\
\hline & \multicolumn{5}{|c|}{ Folha no final do ciclo } \\
\hline Lanço & 41 & 32 & 30 & 35 & \\
\hline Sulco & 43 & 37 & 34 & 20 & 34 \\
\hline
\end{tabular}

proporcional de nutrientes, em particular do $\mathrm{Zn}$, como mostra o presente trabalho. De acordo com os valores apresentados na Tabela 8 , maiores produções de grãos estariam associadas a relações $\mathrm{P} / \mathrm{Zn}$, à época do florescimento, em torno de 100 , confirmando as proposições de Sumner \& Farina (1986), ainda pelas quais valores muito abaixo de 100 também prejudicariam a produção, mas em virtude da deficiência de fósforo na planta.

Pressupõe-se que a exaustão da maior parte do P (Tabelas 3 e 4) e a evidência de alguma mobilização do Zn (Araújo, 2001), das folhas para a formação dos grãos, conduziram à homogeneidade das relações $\mathrm{P} / \mathrm{Zn}$ nas folhas ao final do ciclo (Tabela 8). Assim sendo, a análise da folha abaixo da espiga no florescimento parece ser o procedimento mais adequado para a diagnose da relação $\mathrm{P} / \mathrm{Zn}$, para a qual uma condição de equilíbrio exerce grande influência para o milho, especialmente em situações de manejo objetivando altas produtividades.

\section{Conclusões}

No primeiro cultivo após a aplicação dos tratamentos, as fontes mais solúveis (superfosfato triplo e termofosfato) proporcionam maior produção quando aplicadas a lanço em área total, enquanto o fosfato de Arad é mais eficiente em aplicação localizada no sulco de plantio. $\mathrm{O}$ fosfato de Araxá, quando aplicado no sulco de plantio, promove menor produção.

O uso de superfosfato triplo no sulco de plantio, na dose aplicada, compromete a produtividade do milho, promovendo desordens metabólicas em conseqüência da interação entre $\mathrm{P}$ e $\mathrm{Zn}$. A análise foliar, por ocasião do florescimento, é o procedimento mais adequado para a avaliação do estado nutricional do milho quanto à relação $\mathrm{P} / \mathrm{Zn}$.

\section{Literatura Citada}

ALVES, V. M. C.; VASCONCELLOS, C. A.; FREIRE, F. M.; PITTA, G. V. E.; FRANÇA, G. E. de; RODRIGURES FILHO, A.; ARAUJO, J.M. de; VIEIRA, J. R; LOUREIRO, J. E. Milho. In: RIBEIRO, A. C.; GUIMARÃES, P. T. G.; ALVAREZ V., V. H. (Ed.). Recomendações para o uso de corretivos e fertilizantes em Minas Gerais: 5a. aproximação. Viçosa: Comissão de Fertilidade do Solo do Estado de Minas Gerais, 1999. p. 314-316. 
ANGHINONI, I. Uso de fósforo pelo milho afetado pela fração de solo fertilizada com fosfato solúvel. Revista Brasileira de Ciência do Solo, Campinas, v. 16, n. 3, p. 349-353, set./dez. 1992.

ARAÚJO, I. B. Fontes e modos de aplicação de fósforo na produção e nutrição mineral do milho em primeiro cultivo. 2001. 76 f. Dissertação (Mestrado) - Universidade Federal de Lavras, Lavras.

ARNON, I. Mineral nutrition of maize. Bern: International Potash Institute, 1975. 452 p.

BÜLL, L. T. Nutrição mineral do milho. In: BÜLL, L. T; CANTARELLA, H. (Ed.). Cultura do milho: fatores que afetam a produtividade. Piracicaba: Potafos, 1993. p. 63-145.

CANTARELLA, H. Calagem e adubação do milho. In: BÜLL, L. T; CANTARELLA, H. (Ed.). Cultura do milho: fatores que afetam a produtividade. Piracicaba: Potafos, 1993. p. 147-196.

CLARK, R. B. Mineral element concentrations of corn plant parts with age. Communications in Soil Science and Plant Analysis, New York, v. 6, n. 4, p. 451-464, 1975.

DECARO, S. T.; VITTI, G. C.; FORNASIERI FILHO, D.; MELLO, W. J. Efeito de doses e fontes de zinco na cultura do milho (Zea mays L.). Revista de Agricultura, Piracicaba, v. 58, n. 1/ 2, p. 25-36, jun. 1983.

EMBRAPA. Serviço Nacional de Levantamento e Conservação de Solos. Manual de métodos de análise de solo. 2. ed. Rio de Janeiro, 1997. 212 p. (EMBRAPA - CNPS. Documentos, 1).

GAMBOA, A. La fertilización del maíz. Berna: Instituto Internacional de la Potassa, 1980. 72 p. (Boletim IIP, 5).
GOEDERT, W. J.; LOBATO, E. Avaliação agrônomica de fosfatos em solo de cerrado. Revista Brasileira de Ciência do Solo, Campinas, v. 8, n. 2, p. 97-102, maio/ago. 1984.

GOEDERT, W. J.; SOUSA, D. M. G. Uso eficiente de fertilizantes fosfatados. In: SEMINÁRIO P, Ca, Mg, S E MICRONUTRIENTES: SITUAÇÃO ATUAL E PERSPECTIVA NAAGRICULTURA, 1984, São Paulo. Anais... São Paulo: Manah, 1986. p. 21-53.

GOEDERT, W. J.; LOPES, A. S. Eficiência agronômica de fertilizantes fosfatados para culturas anuais, perenes, pastagens e reflorestamento. In: SEMINÁRIO SOBRE RECUPERAÇÃO DE FÓSFORO, 1987, São Paulo, Anais... São Paulo: Instituto Brasileiro do Fosfato, 1987. p. 24-49.

JARREL, W. M.; BEVERLY, R. B. The dilution effect in plant nutrition studies. Advances in Agronomy, New York, v. 34, p. 197-224, 1981.

KAMINSKI, J.; PERUZZO, G. Eficácia de fosfatos naturais reativos em sistemas de cultivo. Santa Maria: Núcleo Regional Sul da Sociedade Brasileira de Ciência do Solo, 1997. 31 p. (Boletim Técnico, 3).

LONERAGAN, J. F.; WEBB, M. J. Interactions between zinc and other nutrients affecting the growth of plants. In: ROBSON, A. D. (Ed.). Zinc in soil and plants. Dordrecht: Kluwer, 1993. p.119-134. (Developments in Plant and Soil Sciences, 55)

LOPES, A. S. Fosfatos naturais. In: RIBEIRO, A. C.; GUIMARÃES, P. T. G.; ALVAREZ V., V. H. (Ed.). Recomendações para o uso de corretivos e fertilizantes em Minas Gerais: 5a. aproximação. Viçosa: Comissão de Fertilidade do Solo do Estado de Minas Gerais, 1999. p. 65-66. 
LOPES, A. S. The use of phosphate rocks to build up soils phosphorus and increase food production in acid soils: the brazilian experience. In: JOHNSTON, A. E.; SYERS, J. K. (Ed.). Nutrient management for sustainable crop production in Asia. Wallingford: Cab International, 1998. p. 121-131.

MALAVOLTA, E.; VITTI, G. C.; OLIVEIRA, S. A. Avaliação do estado nutricional das plantas: princípios e aplicações. Piracicaba: Potafos, 1997. $319 \mathrm{p}$.

MENGEL, K.; KIRKBY, E. A. Principles of plant nutrition. Bern: International Potash Institute, $1987.687 \mathrm{p}$.

NOVAIS, R. F. Utilização de fosfato naturais de baixa reatividade. In: RIBEIRO, A. C.; GUIMARÃES, P. T. G; ALVAREZ V., V. H. (Ed.). Recomendações para o uso de corretivos e fertilizantes em Minas Gerais: 5a. aproximação. Viçosa: Comissão de Fertilidade do Solo do Estado de Minas Gerais, 1999. p. 62-64.

NOVAIS, R. F.; SMYTH, T. J. Fósforo em solo e planta em condições tropicais. Viçosa: UFV, DPS, 1999. 399 p.

OLSEN, S. R. Micronutrient interactions. In: MORTVEDT, J. J.; GIORDANO, P. M.; LINDSAY, W. L. (Ed.). Micronutrients in agriculture. Madison: Soil Science Society of America, 1972. p. 243-264.

RAIJ, B. van, CANTARELLA, H.; QUAGGIO, J. A.; FURLANI, A. M. C. (Ed.). Recomendações de adubação e calagem para o Estado de São Paulo. Campinas: Instituto Agronômico, 1996. 285 p. (Boletim Técnico, 100).

RAIJ, B. van.; QUAGGIO, J. A. Métodos de análise de solos para fins de fertilidade. Campinas: Instituto Agronômico, 1983. 31 p. (Boletim Técnico, 81).

RITCHEY, K. D.; COX, F. R.; GALRÃO, E. Z.; YOST, R. S. Disponibilidade de zinco para as culturas do milho, sorgo e soja em Latossolo Vermelho-Escuro argiloso. Pesquisa Agropecuária Brasileira, Brasília, v. 21, n. 3, p. 215-225, mar. 1986.

SOUZA, E. C. A.; COUTINHO, E. L. M.; NATALE, W.; BARBOSA, J. C. Respostas do milho à adubação com fósforo e zinco. Pesquisa Agropecuária Brasileira, Brasília, v. 33, n. 7, p. 1031-1036, 1998.

SUMNER, M. E.; FARINA, M. P. W. Phosphorus interaction with other nutrients and lime in field cropping systems. Advances in Soil Science, New York, v. 5, p. 201-236, 1986. 